\title{
Spectrum of gastrointestinal polyps: A tertiary care hospital experience of five years
}

\author{
Milind V. Patil ${ }^{1}$, Ujjwal Rathod ${ }^{2}$, Mahesh Deshmukh ${ }^{3}$, Sangeeta Margam ${ }^{4, *}$ A. D. Kalgutkar ${ }^{5}$ \\ ${ }^{\mathbf{1}}$ Additional Professor, ${ }^{\mathbf{2}}$ Associate Professor, ${ }^{\mathbf{3}, \mathbf{4}}$ Assistant Professor, ${ }^{\mathbf{5}}$ Professor and HOD, Dept. of Pathology, Lokmanya Tilak \\ Municipal Medical College and Lokmanya Tilak Municipal General Hospital, Sion, Mumbai, Maharshtra, India
}

\author{
*Corresponding Author: Sangeeta Margam \\ Email: drsvgoyal@gmail.com
}

Received: $26^{\text {th }}$ December, 2017

Accepted: $2^{\text {nd }}$ April, 2018

\begin{abstract}
Introduction: Polyps of gastrointestinal tract are not uncommon specimens received in surgical pathology laboratory. With advent of advanced endoscopy it is now possible to precisely sample polyps and determine its nature; weather benign, malignant or with malignant potential. Present study was performed with aim to study incidences of various histological types of polyps of gastrointestinal tract, to study its clinical presentation and to study polyps in relation to their size and site, in a tertiary care hospital. Materials and Methods: A retrospective and prospective analysis of 189 cases of gastrointestinal polyps was carried out over a period of eight and half years. Relevant clinical details of patient, size, number, size and presence of stalk etc. were noted. Specimens were studied for gross and microscopic examination after fixation of specimen with 10\% formalin and microscopically examining H \& E slides. They were classified according to site and various histological types.

Results: Overall, we analysed 189 cases of gastrointestinal polyps. Commonest site was large intestine and commonest type was Juvenile polys, followed by neoplastic polyps, hyperplastic polyps, inflammatory pseudo polyps, hamartomatous polyps, inflammatory fibroid polyps and 2 cases of Familial polyposis coli were note.

Conclusion: Present study reveals that gastrointestinal tract had wide spectrum of non-neoplastic as well as neoplastic polyps. They have different clinical significances and therapeutic implications. Histopathology play pivotal role in arriving at final diagnosis which enables to study detail incidences and helps to differentiate non-neoplastic diseases with clinical presentation of malignancy. Incidence of various polyps in based on institutional data and may not reflect incidence of state or nation.
\end{abstract}

Keywords: Gastrointestinal polyps, Adenomatous polyps, Juvenile polyps, Neoplastic polyps.

\section{Introduction}

History of polyps dates back to Greek era and meaning of polyp is "many footed". ${ }^{1}$ Polyps are not very uncommonly encountered lesions in histopathology laboratory sent from surgeons as well as gastroenterologists. Polyps of gastrointestinal tract is board terminology which conveys well circumscribed lesion raised above mucosal surface on gross examination; exact nature of which can be ascertained only on microscopy.

There are several histological types of polyps, which differ in their clinical presentation and particularly in their ability for malignant transformation; therefore management in every patient with polyp depends on an accurate histological diagnosis. ${ }^{2}$ There is variety of polyps with various gross morphological features located in gastrointestinal tract from oesophagus, stomach, small intestine and large intestine, which is being most common. Exact localisation and assessment of macroscopic nature of polyp is improved with advanced endoscopes. Site, size, number, sessile or pedunculated is more possible with current advanced endoscopes. Chromo endoscopy can suggest most probable histological type of polyp with accuracy in exact sample area. Accurate sampling enables to ascertain origin and classify them into epithelial and nonepithelial polyp.

Most important, $80-90 \%$ of colorectal carcinoma originates on background of polyp which undergoes dysplasia, adenocarcinoma in situ and adenocarcinoma sequence. ${ }^{3,4}$

Hence, this study aimed to study frequency, pattern, clinical presentation, and to know exact microscopic nature and risk of malignant transformation. Study can guide gastroenterologists and surgeons for further management and prognosis.

\section{Materials and Methods}

Retrospective and prospective analysis of gastrointestinal polyps was carried out over a period of eight and half years. Data of 189 cases gastrointestinal polyps was culled out from Department of Pathology, Lokmanya Tilak Municipal General hospital, Mumbai over a period of eight and half years. All surgical pathology files were scrutinised and clinical details such as age, sex, presenting complaints like bleeding per rectum, mucous discharge in stool, protrusion, family history and colonoscopy findings were noted. Gross features like the number, location, size, stalk and histopathology findings were recorded. Details of presence and severity of dysplasia in adenomatous polyps were recorded.

Specimen were fixed in buffered $10 \%$ formaldehyde solution and embedded in paraffin wax. Sections were stained Haematoxylin and eosin stains and microscopically examined and polyps were categorised into neoplastic and nonneoplastic polyps. This analysis 
was performed in context of clinical features, gross and histopathology examination.

\section{Results}

Totally 189 polyps were analysed over a period of eight and half years. Frequency of distribution was $67 \%$ in rectum, $21 \%$ in sigmoid colon, $2 \%$ in proximal colon, $4 \%$ in stomach, $2 \%$ in Ileum and duodenum, $1 \%$ in Jejunum and oesophagus each.

Maximum no. Of cases, i.e. 64, belonged to first decade $(52.38 \%)$ and Male: Female ratio was 1.6, followed by 20 cases in $4^{\text {th }}$ decade $(10.35 \%)$, followed by 16 cases in second decade $(8.46 \%)$. This was followed by $5^{\text {th }}$ and $6^{\text {th }}$ decade with equal no. of cases i.e. 15 cases $(7.94 \%)$, followed by third decade with 12 cases
(6.35), followed by $7^{\text {th }}$ decade with 9 cases $(4.77 \%)$, and $8^{\text {th }}$ decade with 2 cases $(1.06 \%)$. Least no. of cases were seen in $9^{\text {th }}$ decade i.e. just single case $(0.52 \%)$.

Location wise large intestine harboured maximum no. of polyps i.e. $(90.48 \%)$, followed by small intestine $4.76 \%$, followed by stomach $3.70 \%$ and lastly $1.06 \%$ in oesophagus. On histological classification Juvenile polyps frequented most commonly consisting of $57 \%$, followed by adenomatous polyps $20 \%$, followed by inflammatory polyps. Remaining $3 \%$ were hamartomatous, $2 \%$ were inflammatory fibroid polyp. Rest of $4 \%$ polyps included squamous paillomas, Brunner's gland hyperplasia, submucosal lipoma, firbroepithelial polyp and gastrointestinal stromal tumours. (Table 2)

Table 1: Site and histological type wise distribution of various polyps

\begin{tabular}{|c|c|c|c|}
\hline Site & Types of polyps & Number & Percentage \\
\hline Esophagus & Squamous Papillomas & 02 & 1.065 \\
\hline \multirow{4}{*}{ Stomach } & Inflammatory fibroid polyp & 02 & \multirow{4}{*}{$3.70 \%$} \\
\hline & Hyperplastic polyp & 01 & \\
\hline & Gastrointestinal stromal tumour & 01 & \\
\hline & Nonspecific Inflmmatory polyp & 03 & \\
\hline \multirow[t]{5}{*}{ Small Intestine } & Brunner's gland hyperplasia & 03 & \multirow[t]{5}{*}{$4.76 \%$} \\
\hline & Adenomatous polyp & 02 & \\
\hline & Inflammatory fibroid polyp & 02 & \\
\hline & Submucosal lipoma & 01 & \\
\hline & Non specific inflammatory polyp & 01 & \\
\hline \multirow{6}{*}{ Large Intestine } & Juvenile polyp & 109 & \multirow[t]{4}{*}{$90.48 \%$} \\
\hline & Adenomatous polyp & 33 & \\
\hline & Hamartomatous polyp & 05 & \\
\hline & Hyperplastic polyp & 11 & \\
\hline & Familial adenomatous polyposis & 02 & \\
\hline & Non specific inflammatory polyp & 11 & \\
\hline Total & & 189 & $100 \%$ \\
\hline
\end{tabular}

Table 2: Incidences of various polyps

\begin{tabular}{|c|c|}
\hline Type of polyp & Incidence in percentage \\
\hline Juvenile polyp & $57 \%$ \\
\hline Adenomatous polyp & $20 \%$ \\
\hline Hyperplastic polyps & $6 \%$ \\
\hline Hamartomatous polyp & $3 \%$ \\
\hline Inflammatory polyp & $8 \%$ \\
\hline Inflammatory fibroid polyp & $2 \%$ \\
\hline Other polyps & $4 \%$ \\
\hline
\end{tabular}

Juvenile polyps were more commonly seen first decade especially during 3-6 years of age group and males outnumbered females.

Table 3: Juvenile polyp-age and sex wise distribution

\begin{tabular}{|l|c|c|c|}
\hline \multicolumn{1}{|c|}{ Age Group } & No. PF Males & No. of Females & Total \\
\hline 0-12 months & 02 & 01 & 03 \\
\hline 13-24 months & 05 & 02 & 07 \\
\hline 25-36 months & 05 & 08 & 13 \\
\hline 37-48 months & 11 & 07 & 18 \\
\hline 49-60 months & 11 & 04 & 15 \\
\hline
\end{tabular}




\begin{tabular}{|c|c|c|c|}
\hline 61-72 months & 11 & 06 & 17 \\
\hline $73-84$ months & 05 & 00 & 05 \\
\hline 85-96 months & 07 & 02 & 09 \\
\hline $97-108$ months & 01 & 04 & 05 \\
\hline $109-120$ months & 04 & 01 & 05 \\
\hline $11-20$ years & 07 & 03 & 10 \\
\hline 21-30 years & 01 & 00 & 01 \\
\hline $31-40$ years & 01 & 00 & 01 \\
\hline Total & 71 & 38 & 109 \\
\hline
\end{tabular}

Commonest site of juvenile polyps was rectum. Smallest polyp measured $0.4 \mathrm{cms}$. in greatest dimension and largest one measured $3 \times 2.5 \times 2.2 \mathrm{cms}$ respectively.

Table 4: Site and size wise distribution of juvenile polyp

\begin{tabular}{|l|c|c|c|c|c|c|c|c|}
\hline \multicolumn{1}{|c|}{ Diameter } & $\begin{array}{c}<\mathbf{0 . 5} \\
\text { cms }\end{array}$ & $\begin{array}{c}\mathbf{0 . 6 - 1} \\
\text { cms }\end{array}$ & $\begin{array}{c}\mathbf{1 . 1 - 1 . 5} \\
\text { cms }\end{array}$ & $\begin{array}{c}\mathbf{1 . 6 - 2} \\
\text { cms }\end{array}$ & $\begin{array}{c}\mathbf{2 . 1 - 2 . 5} \\
\text { cms }\end{array}$ & $\begin{array}{c}\mathbf{2 . 6 - 3} \\
\text { cms }\end{array}$ & $\begin{array}{c}\text { No of } \\
\text { cases }\end{array}$ & \% \\
\hline Rectum & 29 & 41 & 12 & 10 & 01 & 03 & 96 & $88.07 \%$ \\
\hline Sigmoid colon & 03 & 04 & 02 & 03 & -- & 01 & 13 & $11.93 \%$ \\
\hline
\end{tabular}

There were 4 inflammatory fibroid polyps with age ranging from 28 to 65 years. Two were located in stomach, first one presented with chronic gastritis and another with gastric outlet obstruction. Ileal polyps presented with acute abdomen and Intussusception respectively.
There were 5 hamartomatous polyps 3 males and 2 females. Out five two were in sigmoid colon and another two in rectum. Remaining one presented with multiple polyps in recto-sigmoid region.

Totally 12 hamartomatous polyps with male preponderance, 9 in males and 3 in females. Majority were present in fifth and sixth decades and maximum no. was present in recto sigmoid region.

Table 5: Age and sex wise distribution of adenomatous polyp and FAP

\begin{tabular}{|c|c|c|c|c|c|c|c|c|}
\hline & \multicolumn{2}{|c|}{ Tubular } & \multicolumn{2}{c|}{ Villous } & \multicolumn{2}{c|}{ Tubulovillous } & \multicolumn{2}{c|}{ FAP } \\
\cline { 2 - 9 } & Male & Female & Male & Female & Male & Female & Male & Female \\
\hline 11-20yrs & 0 & 0 & 0 & 0 & 0 & 0 & 0 & 0 \\
\hline $21-30 \mathrm{yrs}$ & 1 & 2 & 0 & 0 & 0 & 0 & 0 & 0 \\
\hline 31-40yrs & 1 & 3 & 0 & 0 & 0 & 0 & 0 & 1 \\
\hline $41-50 \mathrm{yrs}$ & 6 & 4 & 0 & 0 & 0 & 0 & 0 & 0 \\
\hline $51-60 \mathrm{yrs}$ & 4 & 0 & 1 & 1 & 3 & 0 & 0 & 0 \\
\hline $61-70 \mathrm{yrs}$ & 2 & 0 & 1 & 0 & 0 & 0 & 1 & 0 \\
\hline $71-80 \mathrm{yrs}$ & 0 & 0 & 0 & 0 & 0 & 0 & 0 & 0 \\
\hline $81-90 \mathrm{yrs}$ & 1 & 0 & 0 & 0 & 0 & 0 & 0 & \\
\hline Total & 17 & 10 & 2 & 2 & 3 & 1 & 1 & 1 \\
\hline
\end{tabular}

Amidst adenomatous polyps, majority of polyps were tubular adenoma followed equally by villous and tublovillous patterns. Male to female ratio of 1.5:1 except in $4^{\text {th }}$ decade where females outnumbered males with male to female ratio of $4^{\text {th }}$ decade with male to female ratio of 1:2.

Table 6: Site and size wise distribution of adenomatous polyps

\begin{tabular}{|l|c|c|c|c|c|c|c|c|c|c|c|c|c|c|c|}
\hline & \multicolumn{4}{|c|}{ Rectum } & \multicolumn{2}{|c|}{ Sigmoid colon } & \multicolumn{3}{c|}{ Proximal Colon } & \multicolumn{3}{c|}{ Ileum \& Jejunum } & \multicolumn{3}{c|}{ Duodenum } \\
\hline Size & T & V & T-V & T & V & T-V & T & V & T-V & T & V & T-V & T & V & T-V \\
\hline$<0.5 \mathrm{cms}$ & 2 & - & - & 3 & - & - & 2 & - & - & - & - & - & - & - & - \\
\hline $0.5-1 \mathrm{cms}$ & 4 & 0 & 1 & 5 & - & 1 & 1 & - & - & 1 & - & - & - & - & - \\
\hline $1-1.5 \mathrm{cms}$ & 0 & 2 & 1 & 5 & - & - & - & - & - & - & - & - & - & - & - \\
\hline $1.5-2 \mathrm{cms}$ & - & - & - & 2 & 1 & - & - & - & - & - & - & - & 1 & - & - \\
\hline$>2 \mathrm{cms}$ & - & 1 & 1 & 1 & - & - & - & - & - & - & - & - & - & - & - \\
\hline Total & 6 & 3 & 3 & 16 & 1 & 1 & 3 & - & - & 1 & - & - & 1 & - & - \\
\hline
\end{tabular}




\section{T- Tubular TV- Tubulovillous V- Villous}

2 cases of familial polyposis coli not included in the table.

We came across thirteen inflammatory polyps; 3 in stomach, one each in duodenum and Ileum, 3 in sigmoid colon and 4 in rectum. Two more inflammatory polyp showed diffuse involvement of large intestine, both elderly males aged 42 years and 45 years respectively.

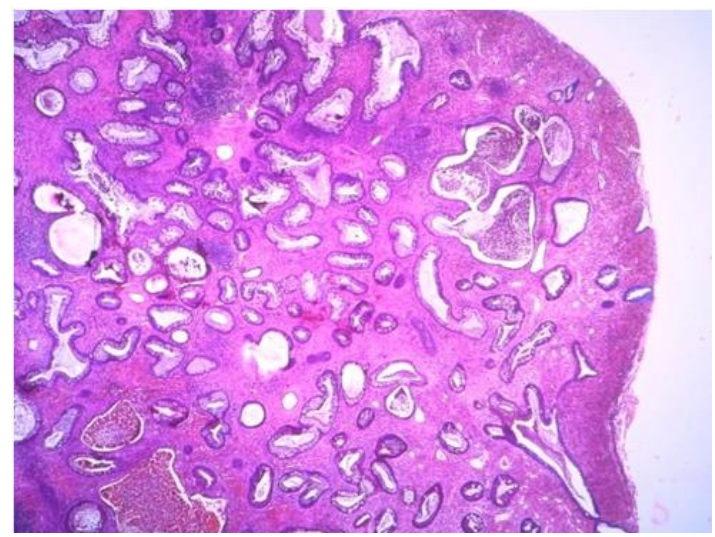

Fig. 1: Juvenile polyp

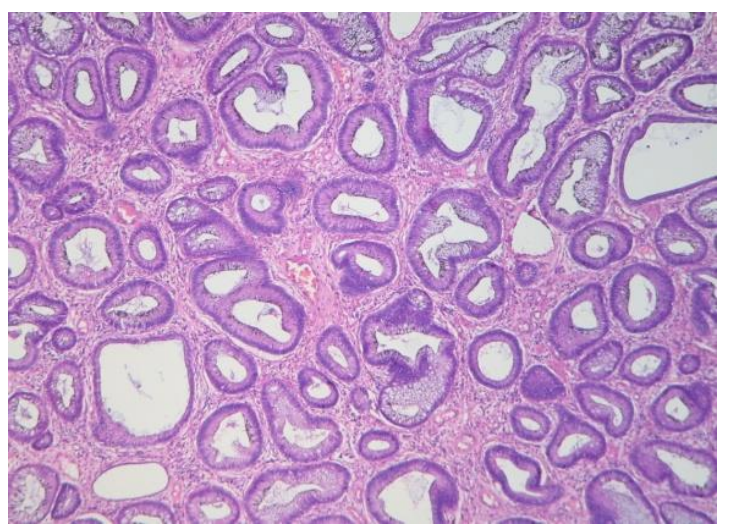

Fig. 2: Tubular adenoma- Neoplastic glands forming tubules

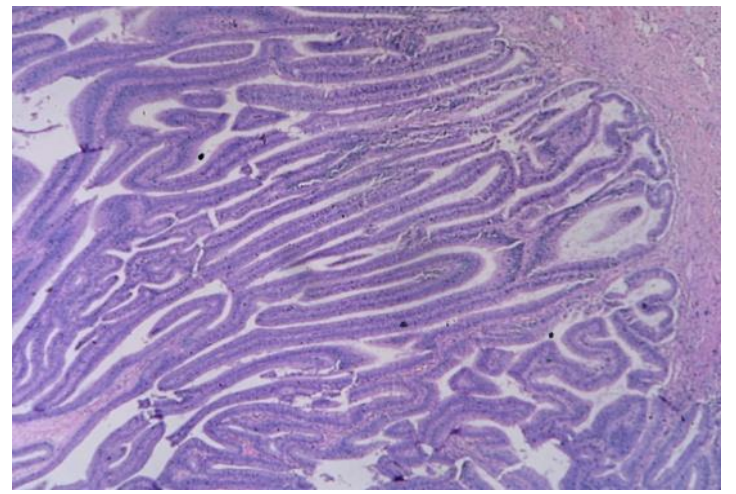

Fig. 3: Villous adenoma- Adenomatous epithelium growing in finger like projections

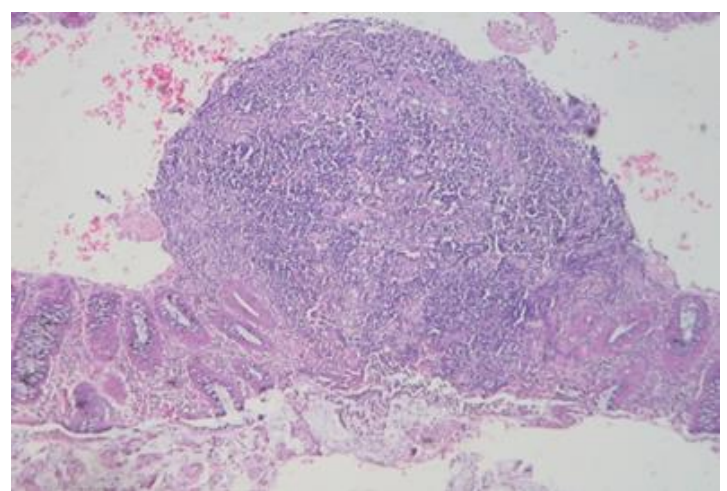

Fig. 4: Inflammatrory fibroid polyp

\section{Discussion}

Polyp is any lesion which projects from the mucosal surface into the lumen. ${ }^{5}$ They are frequently seen in gastrointestinal tract from oesophagus, stomach, small intestine to large intestine.

Various histological types differ in their age of presentation, size, location and clinical presentation. Further, presence of one type of polyp does not necessarily rule out another type of polyp. Moreover, most of the polyps cannot be differentiated on gross examination and malignant transformation or ability for malignant transportation in epithelial polyp holds true on gross examination. Hence it is mandatory than essential that polyp should be removed and studied for histopathological examination. The present study analyses polypoidal lesions of gastrointestinal tract for their frequency, dysplastic malignant transformation in Indian patients and compares the observation with other studies.

It's observed over period of eight band half years from January 1998 to June 2006 that gradual increase in number of polyps mainly due to increased use of endoscopic procedures such as endoscopic polypectomies and biopsies.

In present study frequency distribution of polyps is most frequent in first decade $(52.38 \%)$ and in males; because of high prevalence of juvenile polyps as observed by Rahat $\mathrm{N}^{6,7}$ et al $(31.62 \%)$ and Morson et al. ${ }^{8}$ But females outnumbered males in $4^{\text {th }}$ decade due to increased incidence of adenomatous polyp in that age group. In concordance with other studies large intestine $(90.48 \%)$ is most frequently involved $(1.09 \%)$ in the present study.

We encountered 2 cases of oesophageal polyps $(1.09 \%)$, both in $4^{\text {th }}$ decade. Low incidence of just two cases of oesophageal polyps $(1.09 \%)$ seen were squamous cell papillomas on histology, which coincides with various previous autopsy studies. ${ }^{9}$

Gastric polyps though uncommon, we reported 7 cases $(3.78 \%)$ of gastric polyps, which is in accordance to various studies viz. Rahat et $\mathrm{al}^{5}$ reported incidence of $3.9 \%$ and Gurang $\mathrm{P}$ et al. ${ }^{7}$ Out of seven cases 2 cases were inflammatory fibroid polyps in females in their thirties and forties, single hyperplasic polyp in 62 years 
old female patient, one case of gastrointestinal stromal tumour presenting as polypoidal lesion and three cases of nonspecific inflammatory polyp. Number cases are too small to come to any definite derivation.

In present study we came across 9 small intestinal polyps $(8.48 \%)$, were second most common location for gastrointestinal polyps, out of which four were duodenal, two jejunal and three were Ileal in location.

Two cases of adenomatous polyps were seen in duodenum and another in Jejunum, measuring $0.7 \mathrm{cms}$ and $1 \mathrm{cms}$ in size respectively, which turned out tubular adenomas on histology. Our findings are matching with studies by Rieman et al, ${ }^{10}$ who reported average size of duodenal adenomatous polyps ranging in size from 1 to $8 \mathrm{cms}$ in size. Familial polyposis coli syndrome was ruled out colposcopy.

Two cases of inflammatory fibroid polyps were seen in our study which was located in Ileum, with acute intestinal obstruction and intusuceesption. These findings are similar to Johnston et al,${ }^{11}$ who noted Ileum to be second most common site in their study.

Remaining cases in small intestine were Brunner's gland hyperplasia in 3 cases, in duodenum single case of sub mucous lipoma and remaining case of jejunal nonspecific inflammatory polyp in Ileum.

Colorectal polyps are most frequently seen gastrointestinal polyp in present stduy as reported in literature. Similar observations are done by Rahat $\mathrm{N}$ et $\mathrm{al}^{6}(93.42 \%)$, Gurang P et $\mathrm{al}^{7}(83.6 \%)$ and Morson et $\mathrm{al}^{8}$ also noted rectum was most frequently affected site in their study.

Neoplastic epithelial polyps comprised of $19.58 \%$ in concordance with Morson et $\mathrm{al}^{8}$ who reported similar incidence (20\%).

Juvenile polyps were 109 out of which 104 were solitary, 3 patients presented with two polyps and patients presented with three polyps.

Bleeding per rectum was most common complaint (96\%) of cases, followed by protrusion of polyp (13\%) Similar observations are done by Gupta et al. ${ }^{12,13}$

Juvenile polyps forms major chunk of gastrointestinal polyps, maximum age incidence was in first decade $(88.99 \%)$, followed by second decade (9.17\%0. Thereafter incidence decreased with progressive increase in age. Age ranged from 1 year male to 40 years male with male to female ratio of $1.97 \%$. Dajani et al, ${ }^{14}$ Poddar et $\mathrm{al}^{15}$ and Gupta et $\mathrm{al}^{12}$ and Lee et $\mathrm{al}^{13}$ reported similar age incidence and male predominance.

Most of the juvenile polyps were solitary (96\%),recorded in rectum, while polyps with two or more polyps were seen in sigmoid colon, thus rectum $(88.07 \%)$ was most common site followed by sigmoid colon.

We came across polyps both pedunculated and sessile polyps, average size ranged from $0.6 \%$ to $1 \mathrm{cms}$ $(41.28 \%)$. These findings are comparable to results of Dajani et $\mathrm{al}^{14}(93 \%)$, where most common site was rectum $(96.5 \%)$ followed by sigmoid colon $(2.1 \%)$. Poddar et $\mathrm{al}^{15}$ reported Juvenile polyps in $(76 \%)$ of patients and common site was rectum $971.2 \%$ ) followed by sigmoid colon (19.5\%), polyps were both sessile and pedunculated.

Different observations were seen in study done by Gupta et al, ${ }^{12}$ who reported 54\% of polyps were located in recto sigmoid region, $14 \%$ in descending colon while $31 \%$ in proximal colon implicating that higher frequency of polyps in Indian children as seen in present study. Exact reason for this are unclear but may be related to genetic or environmental factors.

Although juvenile polyps are categorised under hamartomatous polyp there is a risk of malignant transformation following adenoma- dysplasiacarcinoma sequence is seen. This risk is small in paediatric population as observed by us. Only three cases $(2.75 \%)$ showed focal adenomatous transformation.

Dajani et $\mathrm{al}^{14}$ reported dysplasia in $2.23 \%$ of cases, where as Poddar et $\mathrm{a}^{15}$ reported adenomatous change in $5.0 \%$ of cases. Adenomatous change is as high as $47 \%$ in one series. Further recurrence rate of juvenile polyps after polypectomy is low, about which we could not conclude as we lost patients to follow up.

Neoplastic polyps are important because of its size, site and morphology are closely associated with development of carcinoma. Reported incidence varies from as high as $64 \%$ in Hawai to as low as $1.5 \%$ in Iran.

We came across 35 adenomatous polyps. Twentyfour patients with clinical presentation of bleeding per rectum, four patients with complaints of mucous discharge with bleeding PR and seven patients were asymptomatic. The peak age incidence of adenomatous polyps was in age group of 51-60 years $(24.32 \%)$, in commensurate with average age of 55.8 years reported by Irfan Ahmed et al. ${ }^{16}$ Age ranged from 13 years to 85 years old males. The youngest patient was 13 years old girl whose elder sister (18 years) presented with complaints of blood in stools, while their father underwent surgery for polyposis lesion. Another patient presented in second decade with family history of adenomas.

Its well established fact that familial polyposis coli have familial predesposition and off springs and children are at increased risk of polyps and colorectal cancer without size and type of polyp. This observation is also reported by Wanewar et al. ${ }^{17}$

In our study male to female ratio was $1.5: 1$, close to 2.3:1 observed by Irfan Ahmed et al. ${ }^{16}$

Location of polyps in order of frequency was sigmoid colon $51.42 \%$, followed by rectum $34.28 \%$ and proximal colon $8.5 \%$.

Two cases of polyposis were excluded as site of localisation could not be affixed because of diffuse involvement of colon.

In current study out of 35 majority of adenomas measured between 1 to $1.5 \mathrm{cms}$ in size and on histology majority were tubular $(90 \%)$. These observations are 
similar to those by Shinya et al, ${ }^{18}$ who concluded that adenomatous polyps of size between 0.5 to $1 \mathrm{cms}$ in $90 \%$ cases turned out to be tubular adenomas.

On histology, distribution of polyps was tubular adenomas (77.16\%) as predominant pattern followed by villous and tubule-villous adenomas in equal in number $(11.42 \%)$.

Irfan Ahmed et $\mathrm{al}^{16}$ observed most frequently type of polyps as tubular adenomas (59\%), comparatively lower incidence than present study $(89.16 \%)$. Similar observations of most common frequency of tubular adenomas are done by Chitale et $\mathrm{al}^{19}(64 \%)$. We came across two cases of familial polyposis coli which were excluded because of exact localisation of site.

6 cases $(17.14 \%)$ showed high grade dysplasia and one more polyp $92.85 \%$ ) showed invasive carcinoma.

Dysplasia was seen commonly in polyps having largest diameter of 1.5 to $2 \mathrm{cms}$. Euscher et $\mathrm{al}^{20}$ reported $28 \%$ high grade dysplasia in $28 \%$ and invasive carcinoma in $12 \%$ in polyps of large intestine more than $2 \mathrm{cms}$ in size.

Two cases of familial adenomatosis coli were reported in current study. First case was 26 years old female presented with complaint of bleeding PR since one year with family history of colectomy done in father. Colonoscopy revealed multiple polyps involving large intestine which on gross examination varied in size from 0.2 to $1 \mathrm{cms}$ on colectomy. Histopathology examination confirmed these polyps to be tubular adenomas mainly and few with tubulovillous pattern. No syndromic association was seen on detailed work up.

Another case of 65 years old male presented with complaints of chronic diarrhoea and mucous discharge since 2 to 3 years. Colonoscopy revealed thousands of polyps carpeting entire colon, all of them were sessile on gross examination, which turned out to be tubular adenomas on microscopy. Four polyps were large, warty like growth, which showed malignant transformation with metastasis to regional lymph nodes. Again syndromic association was ruled out by extensive work up. To, conclude adenomas are harbinger of adenocarcinoma of colon in a particular population.

Polyps similar in size on gross examination are by and large tubular adenomas, histopathology of which changes to villous pattern and degree of dysplasia from low to high grade with increase in size. Early detection with surveillance colonoscopy is must in familial polyposis coli as untreated and unmonitored polyps eventually progress to adenocarcinoma.

Total 12 cases of hyperplastic polyps were seen predominantly in males located mainly in rectosigmoid region, sessile in configuration, measuring less than 0.5 $\mathrm{cms}$ in size except one, which measured $1 \times 1 \times 0.5 \mathrm{cms}$ with stalk. No dysplasia or malignant transformation was noted.

In present study five cases of hamartomatous polyps were seen. One patient was a 35 years old lady with history of mucousal discharge in stools along with abdominal pain, coloscopy of which revealed multiple polyps in recto sigmoid colon. Pedunculated varied in size from $5 \mathrm{~mm}$ to $2 \mathrm{cms}$. Largest measuring $2 \mathrm{X} 2.5 \mathrm{cms}$. in size. No syndromic association was seen. Remaining four patients presented with bleeding per rectum. Grossly solitary, pedunculated two located in rectum and two in sigmoid colon. Three patients belonged to first and second decade without any sex predilection.

Histopathology revealed characteristic arborising branching of muscularis mucoase into lamina propria with overlying normal epithelium. No dysplasia or adenomatous change were detected in all five cases. Incidence of adenomatous foci reported by various authors are $12.7 \%$ by Hizaw et al, ${ }^{21} 5.8 \%$ by Narita et al. ${ }^{22}$ Only single case of carcinomatous change in nonsyndromic Peutz-Jeghars hamartomatous polyp is reported.

In present study a single case of fibroepithelial polyp of rectum is seen.

Total 11 cases of inflammatory pseudo polyp were seen in large intestine. Just more than half patients were seen in third and fourth decade and youngest patient was 22 years old man. Chronic diarrhoea and abdominal discomfort was most common clinical presentation in most of the patients, with recto sigmoid $(41.17 \%)$ region was most common site as seen by Rahat et al. ${ }^{6}$ Polyps in 9 patients were single, solitary with maximum diameter of $1 \mathrm{cms}$. Two patients were aged 42 years and 45 years were diagnosed as Ulcerative colitis. As reported in literature histopathology features seen in present series, polyps showed dilated crypts, mucosal oedema with variable degree of inflammatory infiltrate of lymphocytes and plasma cells, most of them covered with granulation cap.

\section{Conclusion}

This study would help to classify polyps and predict which polyps has malignant potential. Biological progression and subsequent clinical management of patient can be effectively planned on histological classification. Further studies of genomic and molecular analysis could help in understanding pathogenesis and its biological behaviour with respect to adenoma carcinoma sequence in details. This study is single tertiary care hospital based. Muliticentric studies in this area would be desirable.

\section{References}

1. Anderson KM, Mosby dictionary. Ed 4;St Louis: Mosby. 1994:1245-1246.

2. Kim EC, Lance P. Colorectal Polyps and their relationship to cancer. Gastroenterol Clin North Am. 1997;26(1):1-14.

3. Kinzler KW, Vogelstein B. Lessons from hereditary colorectal cancer. Cell 1996;87:159-70

4. Fleming, M., Ravula, S., Tatishchev, S. F., \& Wang, H. L. (2012). Colorectal carcinoma: Pathologic aspects. Journal of Gastrointestinal Oncology. 3(3):153173. 
5. Sternberg: Surgical Pathology, Lippincot; $4^{\text {th }}$ Ed, vol. 2:1543-1568

6. Rahat N. Morphological study of the polypoid lesions of the gastrointestinal tract. PakJ Med Sci. 2005;21(3):31824.

7. Gurung P, Hirachand S, Pradhanang S and Lama S. Histopthological study of gastrointeinal polyps in a Tertiary Care Hospital, Nepal Journal of Institute of Medicine. 2014;36(1):64-68.

8. Morson DC DownsonIan MP: Gastrointestinal Pathology; Ed2, Oxford; Balckwell Sci Pub. 1979:140-714.

9. Quitamido M, Benson J. Squamous Papilloma of oesophagus, a case report and review of literature. Am J gastroenterology. 1992;10:668-673.

10. Riemann Z F, Hartman D, Schilling D: Frequency of small bowel polyp in patient with duodenal adenoma but without familial adenomatous polyposis. Gastroenterology: 2000:44(3):235-238.

11. Fenoglio-Preiser CM, Noffsinger AE, Stemmermann GN, Lantz PE, Isaacson PG. Gastrointestinal Pathology: An Atlas and Text. 3rd edition. Wolters Kluwer/Lippincott Williams \& Wilkins; 2008.

12. Johnstone JM, and Morson Bg, Eosinopillic gastroenteritis . Histopathology, 1978(2):335-348.

13. Sandip Gupta, MD Joseph Filtizerad. Experience of juvenile polyp in N. American children: A need for pancolposcopy. Am J Gastroenterology, 2001,6:16951697.

14. Lee, B. G., Shin, S. H., Lee, Y. A., Wi, J. H., Lee, Y. J., \& Park, J. H. (2012). Juvenile Polyp and Colonoscopic Polypectomy in Childhood. Pediatric Gastroenterology, Hepatology \& Nutrition, 15(4):250-255. http://doi.org/10.5223/pghn.2012.15.4.250
15. Dajani YF, Kamal MF: Colorectal juvenile polyp an epidemiological and histological study of 144 cases in Jordonins. Histopathology 1984;8:765-779.

16. Ujwal Poddar, BR Thappa, Kim Vaiphei. Colonic polyps experience of 236 Indian children. Am J Gastroenterology. 1998(93):619-622.

17. Irfan Ahmed. Stduy of colorectal poly. 2006, JCPSC, 364-367.

18. Wanewar. Risk of colorectal cancer in families of patients with adenomatous polyps. N.E.J.M: 1996; correspondence page 1339 .

19. Shinya $\mathrm{H}$, et al. Morphology, anatomic distribution and cancer potential of colonic polyps. Ann Surg. 1979;190:679-83.

20. Chitale. Pathology of colorectal polyp and overview: Bombay Hospiptal journal 2004.

21. Elizabeth Eusche, Theodrore H: large colorectal adenomas and approach to pathological evaluation. Am J Clin Path. 2001:116:336-340.

22. Hizawa K, Lida M. Neoplastic transformation arising in Peutz-Jeghars polyposis. Disease of colon and rectum: 1993;36:953-957.

23. Narita T, Ohnuma H: Peutz -Jeghars syndrome with osseous metaplasia of intestinal polyp. Path Int. 1995:45:388-390.

How to cite this article: Patil M.V, Rathod U, Deshmukh M, Margam S, Kalgutkar A. D. Spectrum of gastrointestinal polyps: A tertiary care hospital experience of five years. Indian $\mathrm{J}$ Pathol Oncol. 2018;5(4):656-662. 